\title{
EL IMPUESTO SOBRE DEPÓSITOS DE LAS ENTIDADES DE CRÉDITOS: EJEMPLO PARADIGMÁTICO DE LA LIMITADA AUTONOMÍA FINANCIERA DE LAS COMUNIDADES AUTÓNOMAS
}

\author{
Alejandro Platero Alcón
}

doi: 10.18543/ed-64(2)-2016pp189-224

\begin{abstract}
SUMARIO. INTRODUCCIÓN. I. EL IMPUESTO SOBRE DEPÓSITOS DE ENTIDADES DE CRÉDITO. A) La autonomía financiera de las comunidades autónomas. B) El caso de Extremadura: Comunidad pionera en el establecimiento del impuesto sobre depósitos en entidades de crédito. II. El enjuiCiamiento AL IDEC EXTREMEÑo. A) Recurso de inconstitucionalidad. B) Análisis de la Sentencia del Tribunal Constitucional número 210/2012 de 14 de noviembre. III. REACCIONES A LA DECLARACIÓN DE CONSTITUCIONALIDAD DEL IDEC EXTREMEÑO. A) La reacción del Estado Español. B) La respuesta autonómica. IV. ANÁLISIS DE LA SENTENCIA DEL TRIBUNAL CONSTITUCIONAL NÚMERO 26/2015 DE 19 DE FEBRERO. V. LA REGULACIÓN ACTUAL DEL IMPUESTO.
\end{abstract}

\section{INTRODUCCIÓN}

La autonomía financiera de las Comunidades Autónomas es una cuestión controvertida y compleja dentro de España. La historia tributaria se encuentra llena de ejemplos donde se han producido grandes conflictos entre el Estado y las Comunidades Autónomas. En el presente trabajo se analizará uno de estos ejemplos de recorrido reciente y actual, como es la problemática surgida con el impuesto sobre depósitos de entidades de crédito. 
El impuesto sobre depósitos de entidades de crédito tiene un origen autonómico, ya que fue creado por una Comunidad Autónoma, concretamente la Extremeña. Extremadura, haciendo uso de su potestad tributaria decide en el año 2001 crear un tributo propio, tributo directo que gravaría los depósitos que se constituyeran en las entidades de crédito situadas dentro de su territorio, siempre que existiera la obligación de la entidad de crédito de reintegrar dichos depósitos. Mediante la creación de esta figura, Extremadura pretendía obtener unos ingresos para poder desarrollar sus gastos, haciendo colaborar a las entidades de crédito, pero este acontecimiento, ha supuesto el origen de una cronología de hechos, que han convertido al impuesto sobre depósitos de entidades de crédito, en una de las figuras tributarias más conflictivas en la actualidad.

El Estado Español, por cuestiones de legalidad para unos, o por cuestiones de cooperación con las entidades de crédito para otros, no compartió con el legislador Extremeño, la idea de que una entidad de crédito pudiera contribuir al sostenimiento de los gastos públicos, a través de un impuesto de semejantes características. En efecto, el gobierno en representación del Estado decide en el año 2002, interponer un recurso de inconstitucionalidad contra la regulación autonómica del impuesto Extremeño, argumentando el mismo, como en el cuerpo del trabajo se expondrá, en los límites tributarios de las comunidades autónomas, en relación con los tributos estatales y los tributos locales.

El Tribunal Constitucional en el año 2012, consideró legal y valido al impuesto sobre depósitos de entidades de crédito. A partir de este fallo, se vuelven a desencadenar una serie de hechos, que demuestran que el sistema tributario autonómico existente, fundamentalmente en lo referido al sistema de reparto de competencias entre las comunidades autónomas y el Estado es deficiente. En efecto, como después se expondrá, tras el pronunciamiento del Alto Tribunal, tanto el Estado como las comunidades autónomas deciden legislar a toda prisa esta figura, cada uno con fines distintos.

El Estado Español crea en diciembre del año 2012, un impuesto de similares características al Extremeño, a través de una Ley ordinaria, con la única salvedad de fijar un tipo de gravamen cero, lo que suponía la ausencia de recaudación por el mismo. El principal fin de esta regulación, no puede ser otra, que impedir a las Comunidades Autónomas regular el mismo, ya que, como después se expondrá, la norma reguladora de la financiación de las comunidades autónomas, prohíbe este supuesto de doble imposición. Pero, como se decía anteriormente, no solo el Estado reacción con rapidez a este pronunciamiento, sino que varías Comunidades Autónomas también actuaron con la misma celeridad.

Abanderando la reacción de las Comunidades Autónomas, se encuentra, Cataluña. Dicha comunidad, decide tramitar un impuesto sobre depósitos de 
entidades de crédito a la par que el Estado Español, buscando una finalidad concreta, como es acceder al sistema de compensación previsto en la normativa de financiación autonómica. En efecto, una de las principales controversias expuestas posteriormente en relación a la regulación estatal del impuesto objeto de estudio, es el sistema de compensación establecido en la misma. La norma que regula el sistema de financiación autonómica determina que en caso de que el Estado actúe gravando un hecho imponible, gravado con anterioridad por las Comunidades Autónomas, éste deberá arbitrar un sistema de compensación, para paliar su disminución de ingresos. El Estado decidió establecer un sistema de compensación en un primer término, a través del cual solo compensaría a las comunidades que tuvieran el impuesto en vigor, antes de la aprobación del tributo estatal. De facto, solo se compensaría a tres comunidades: Extremadura, Andalucía y Canarias.

Este sistema de compensación, la imposición de un tipo de gravamen cero, y su método de aprobación, provocaron numerosas controversias, que tuvieron que ser resueltas por el Tribunal Constitucional en febrero del año 2015, declarando legal el impuesto Estatal.

En último lugar, se analizará en el presente trabajo, la regulación actual del impuesto sobre depósitos de las entidades de crédito Estatal, y la controversia suscitada con la misma, de la que también, tuvo que pronunciarse el Tribunal Constitucional en el mes de octubre de 2015.

\section{EL IMPUESTO SOBRE DEPÓSITOS DE ENTIDADES DE CRÉDITO}

\section{A) La autonomía financiera de las comunidades autónomas}

La primera regulación existente acerca del impuesto sobre depósitos de las entidades de crédito, fue una regulación de una comunidad autonómica, concretamente la comunidad autónoma de Extremadura. Dicha comunidad, creó en el año 2001 este impuesto a través, de la Ley de la Asamblea de Extremadura 14/2001 de 29 de noviembre, reguladora del impuesto sobre depósitos de las entidades de crédito ${ }^{1}$.

La capacidad normativa tributaria de las comunidades autónomas se encuentra recogida en la norma suprema del ordenamiento jurídico español, la Constitución Española de $1978^{2}$ (en acrónimo CE) concretamente, en los

${ }^{1}$ Ley de la Asamblea de Extremadura 14/2001 de 29 de noviembre, reguladora del impuesto sobre depósitos de las entidades de crédito, «BOE» núm. 31, de 5 de febrero de 2002.

${ }^{2}$ Constitución Española, «BOE» núm. 311, de 29 de diciembre de 1978. 
artículos $133.2^{3}$ y $157.1^{4}$. De la regulación conjunta de ambos artículos, se obtiene, que las comunidades autónomas ostentan capacidad normativa tributaria, y que entre otras figuras, podrán crear la figura genérica objeto de análisis en el presente trabajo, es decir, un impuesto propio, ya que «uno de los exponentes de la realización de la autonomía financiera por parte de las comunidades autónomas es su capacidad para poder decidir sobre sus propios ingresos, y la realización de esta capacidad es el poder de crear tributos» ${ }^{5}$.

Para poder realizar un exhaustivo análisis del impuesto sobre depósitos de las entidades de crédito (en acrónimo IDEC), es necesario, partir previamente de la exposición del concepto de impuesto. Este concepto, previene de uno anterior como establece la Ley General Tributaria 58/2003, de 17 de diciembre $^{6}$ (en acrónimo LGT), como es el concepto de tributo. Los tributos pueden son definidos positivamente como «los ingresos públicos que consisten en prestaciones pecuniarias exigidas por una Administración pública como consecuencia de la realización del supuesto de hecho al que la ley vincula el deber de contribuir, con el fin primordial de obtener los ingresos necesarios para el sostenimiento de los gastos públicos» $\rangle^{7}$. Los tributos autonómicos, serán aquellos «creados por leyes autonómicas, gestionados por administraciones autonómicas, y destinados sus productos a los presupuestos autonómicos, en el conjunto del sistema de financiación autonómica» ${ }^{8}$. Según el artículo 2.2 del citado texto legal, los tributos se dividen en tasas, contribuciones especiales e impuestos, siendo el punto c) de dicho precepto el que otorga la siguiente definición de impuesto «son los tributos exigidos sin contraprestación cuyo hecho imponible está constituido por negocios,

3 Artículo 133.2 de la Constitución Española: «Las Comunidades Autónomas y las Corporaciones locales podrán establecer y exigir tributos, de acuerdo con la Constitución y las leyes».

${ }^{4}$ Artículo 157.1 de la Constitución Española: «Los recursos de las Comunidades Autónomas estarán constituidos por: a) Impuestos cedidos total o parcialmente por el Estado; recargos sobre impuestos estatales y otras participaciones en los ingresos del Estado. b) Sus propios impuestos, tasas y contribuciones especiales. c) Transferencias de un Fondo de Compensación interterritorial y otras asignaciones con cargo a los Presupuestos Generales del Estado. d) Rendimientos procedentes de su patrimonio e ingresos de derecho privado. e) El producto de las operaciones de crédito.

${ }_{5}$ Galapero Flores, Rosa, «El carácter constitucional del impuesto sobre los depósitos de las entidades de crédito de la comunidad autónoma de Extremadura», Anuario de la Facultad de Derecho, XXI (2003): 84-86.

${ }^{6}$ Ley 58/2003, de 17 de diciembre, General Tributaria, «BOE» núm. 302, de 18 de diciembre de 2003.

7 Artículo 2.1 de la Ley 58/2003, de 17 de diciembre, General Tributaria.

${ }^{8}$ Lago Montero, José María, El poder tributario de las Comunidades Autónomas (Cizur Menor: editorial Aranzadi, 2000), 40 y 41. 
actos o hechos que ponen de manifiesto la capacidad económica del contribuyente» ${ }^{9}$.

Antes de continuar con la exposición del IDEC, es necesario, matizar algunos aspectos de la anterior definición legal, que ayudaran a interpretar más fácilmente la naturaleza jurídica del impuesto sobre depósitos de entidades de crédito. Así, es necesario destacar que parte de la doctrina critica la alusión al término contraprestación, «puesto que esta, en sentido jurídico, no es más que la prestación debida por una de las partes de un negocio jurídico bilateral a cambio de otra a su favor (...) lo que determina el nacimiento de la obligación es exclusivamente la realización del presupuesto de hecho previsto en la ley, pero en modo alguno una contraprestación de una de las partes ${ }^{10}$. Además, el precepto establecía que el hecho imponible ${ }^{11}$ del impuesto se encuentra formado por tres presupuestos de hecho: actos, negocios y hechos. De lo anterior se extrae que «el hecho imponible del impuesto puede tener cualquier contenido, siempre que revele capacidad económica en quien lo realice» ${ }^{12}$.

Ahora bien, una vez determinada la capacidad normativa tributaria de las comunidades autónomas, es necesario recordar que esta capacidad no es absoluta, sino que tiene una serie de límites, fundamentalmente expuestos en la Ley Orgánica 8/1980, de 22 de septiembre, de Financiación de las Comunidades Autónomas ${ }^{13}$ (en acrónimo LOFCA). Estos límites, que serán importantes matizar en este apartado, debido a su correspondencia en los aspectos fundamentales del IDEC, se pueden dividir en dos grandes grupos, estatales y locales:

a) Estatales: Este límite aparece consagrado en el artículo 6.2 LOFCA que establece que «los tributos que establezcan las Comunidades Autónomas no podrán recaer sobre hechos imponibles gravados por el Estado. Cuando el Estado, en el ejercicio de su potestad tributaria originaria establezca tributos sobre hechos imponibles gravados por las Comunidades Autónomas, que supongan a éstas una disminución

9 Artículo 2.2 c) de la Ley 58/2003, de 17 de diciembre, General Tributaria.

${ }^{10}$ Merino Jara, Isaac, Lucas Durán, Manuel, Fernández Amor, José Antonio, García Calvente, Yolanda, García Luis, Tomás, Manzano Silva, Elena, Ruiz Garijo, Mercedes, Vaquera García, Antonio, Derecho Financiero y Tributario: Parte General (Madrid: Tecnos, 2011): 92 y 93.

11 Artículo 20 de la Ley 58/2003, de 17 de diciembre, General Tributaria:» El hecho imponible es el presupuesto fijado por la ley para configurar cada tributo y cuya realización origina el nacimiento de la obligación tributaria principal».

12 Ibidem., página 92

13 Ley Orgánica 8/1980, de 22 de septiembre, de Financiación de las Comunidades Autónomas, «BOE» núm. 236, de 01/10/1980. 
de ingresos, instrumentará las medidas de compensación o coordinación adecuadas en favor de las mismas» ${ }^{14}$.

El anterior límite prohíbe a las comunidades autónomas establecer tributos que contengan hechos imponibles ya grabados por el Estado, cuestión de la que se acusó al impuesto sobre depósitos de las entidades de créditos extremeño, como después se expondrá. Parte de la doctrina y la jurisprudencia han perfilado el alcance del artículo 6.2 LOFCA, fundamentalmente abundando en la distinción existente entre hecho imponible y materia imponible, de suerte tal que «por materia imponible u objeto del tributo debe entenderse toda fuente de riqueza, renta o cualquier otro elemento de la actividad económica que el legislador decida someter a imposición, realidad que pertenece al plano de lo fáctico, mientras que por hecho imponible, por el contrario estamos ante un concepto jurídico, siendo posible que en relación con una misma materia impositiva, el legislador pueda seleccionar distintas circunstancias que den lugar a otros tanto hechos imponibles, determinantes a su vez de figuras tributarias diferentes ${ }^{15}$. En el mismo sentido se pronuncia la sentencia del Tribunal Constitucional (en acrónimo TC) 289/2000, de 30 de noviembre, ya que en su fundamento jurídico cuarto establece que «el alcance del concepto de materia imponible, es más amplio que el de hecho imponible al que se refiere el apartado 2 del artículo 6 LOFCA (...) lo que el artículo 6.2 prohíbe, en sus propios términos, es la duplicidad de hechos imponibles, estrictamente».

b) Locales: Este límite aparece consagrado en el artículo 6.3 LOFCA que establece que «los tributos que establezcan las Comunidades Autónomas no podrán recaer sobre hechos imponibles gravados por los tributos locales. Las Comunidades Autónomas podrán establecer y gestionar tributos sobre las materias que la legislación de Régimen Local reserve a las Corporaciones locales. En todo caso, deberán establecerse las medidas de compensación o coordinación adecuadas a favor de aquellas Corporaciones, de modo que los ingresos de tales Corporaciones Locales no se vean mermados ni reducidos tampoco en sus posibilidades de crecimiento futuro» ${ }^{16}$.

Este precepto es similar al analizado anteriormente, ya que en el mismo, se prohíbe que las comunidades autónomas creen tributos sobre hechos

${ }^{14}$ Artículo 6.2 LOFCA.

15 CheCA GonzÁlez, Clemente. «El impuesto sobre tierras infrautilizadas de la Comunidad Autónoma Andaluza. Comentario a la Sentencia TC 37/1987 de 26 de Marzo», en Impuestos. Revista de Doctrina, Legislación y Jurisprudencia, tomo I (1987): 674-675.

${ }^{16}$ Artículo 6.3 LOFCA. 
imponibles gravados por los tributos locales, mientras que en el anterior, se prohibía que las comunidades autónomas crearan tributos sobre hechos imponibles gravados por el Estado. En relación a la potestad tributaria de las entidades locales, debe hacerse referencia a la Ley 39/1988, de 28 de diciembre, reguladora de las Haciendas Locales ${ }^{17}$ (en acrónimo LRHL), que establece en su artículo 60, que los ayuntamientos exigirán los siguientes impuestos: impuesto de bienes inmuebles, impuesto sobre vehículos de tracción mecánica y el impuesto sobre actividades económicas. Es importante, resaltar la presencia del impuesto sobre actividades económica, impuesto que será objeto de controversia posteriormente, cuando se analice la legalidad del IDED. Además, podrán establecer y exigir el Impuesto sobre Construcciones, Instalaciones y Obras y el Impuesto sobre el Incremento de Valor de los Terrenos de Naturaleza Urbana.

En vista de la exposición anterior, «cualquier otra materia imponible no estaría reservada a las Haciendas Locales, por tanto, siempre y cuando tampoco se vulnerasen los objetos sobre los que recaen los impuestos estatales, las comunidades autónomas podrán establecer libremente cualquier gravamen sobre una materia distinta de las reseñadas, puesto que no estaría reservada a las Haciendas Locales y, por tanto, sería susceptible de constituir el objeto de un tributo autonómico» ${ }^{18}$.

Los anteriores límites de la capacidad normativa tributaria autonómica, se encuentran relacionados con los supuestos de doble imposición, como establece la sentencia del Tribunal Constitucional 19/1987, de 17 de febrero en su fundamento jurídico cuarto, cuando dicta «al impedir a las comunidades autónomas establecer tributos equivalentes a los ya establecidos por el estado y las entidades locales lo que se pretende evitar es, en suma, que se produzcan dobles imposiciones no coordinadas, garantizando de esta manera que el ejercicio de poder tributario por los distintos niveles territoriales sea compatible con la existencia de un sistema tributario en los termino exigidos por la constitución española».

Además de los anteriores limites, se debe destacar que la Ley Orgánica de Financiación de las Comunidades Autónomas establece en su artículo 9 una serie de previsiones, consideradas como concreciones del principio de territorialidad constitucional ${ }^{19}$, que deben ser tenidas en cuentas por las Comunidades Autónomas:

${ }^{17}$ Ley 39/1988, de 28 de diciembre, reguladora de las Haciendas Locales, «BOE» núm. 313, de 30 de diciembre de 1988.

18 Álvarez Arroyo, Francisco, «Incidencia de las Comunidades Autónomas en el sistema financiero y tributario local: Análisis jurídico del artículo 6.3 LOFCA y sus posibilidades de aplicación», Revista Quincena Fiscal 14 (1994), 4-5.

19 Artículo 157.2 de la Constitución Española: «Las Comunidades Autónomas no podrán en ningún caso adoptar medidas tributarias sobre bienes situados fuera de su terri- 
a) No podrán sujetarse elementos patrimoniales situados, rendimientos originados ni gastos realizados fuera del territorio de la respectiva Comunidad Autónoma.

b) No podrán gravarse, como tales, negocios, actos o hechos celebrados o realizados fuera del territorio de la comunidad impositora, ni la transmisión o ejercicio de bienes, derechos y obligaciones que no hayan nacido ni hubieran de cumplirse en dicho territorio o cuyo adquirente no resida en el mismo.

c) No podrán suponer obstáculo para la libre circulación de personas, mercancías y servicios capitales, ni afectar de manera efectiva a la fijación de residencia de las personas o a la ubicación de Empresas y capitales dentro del territorio español, de acuerdo con lo establecido en el artículo segundo, uno, a), ni comportar cargas trasladables a otras Comunidades.

El Tribunal Constitucional se ha pronunciado acerca de este principio de territorialidad, expresando en su sentencia 168/2004, de 6 de octubre, que los principios de territorialidad y de unidad de mercado «no pueden ser interpretados en unos términos que impidan a las instancias autonómicas, en el ejercicio de sus competencias, adoptar decisiones cuyas competencias puedan proyectarse sobre otros lugares del territorio nacional».

El anterior precepto (artículo 9 LOFCA) es importante de cara al análisis de la naturaleza jurídica del impuesto sobre depósitos de las entidades de crédito, ya que, como después se expondrá, su legalidad fue cuestionada entre otras cuestiones, por impedir la libre circulación de capitales (apartado c) y por gravar actos celebrados fuera de su territorio (apartado b).

\section{B) El caso de Extremadura: Comunidad pionera en el establecimiento del impuesto sobre depósitos en entidades de crédito.}

El impuesto sobre depósitos de las entidades de crédito en Extremadura se crea como se dijo anteriormente, por la Ley de la Asamblea de Extremadura 14/2001 de 29 de noviembre, reguladora del impuesto sobre depósitos de las entidades de crédito. De la exposición de motivos de la ley se extraen varias notas importantes, así este impuesto contiene carácter directo y no repercutible jurídicamente y se encuentra destinado a gravar, la obtención de fondos reembolsables por parte de Bancos, Cajas de Ahorro, y Cooperativas de Crédito, que operen en Extremadura. Esta ley se divide en 19 artículos, a través de los cuales se establecen los elementos esenciales del IDEC.

torio o que supongan obstáculo para la libre circulación de mercancías o servicios.» 
El artículo número 1 de la Ley autonómica, establece la naturaleza del impuesto, siendo el mismo un impuesto de carácter directo, destinado a gravar los fondos reembolsables de las entidades de crédito. Un impuesto es directo cuando "grava manifestaciones inmediatas de capacidad económicas, y es el sujeto pasivo el que está llamado a soportar el impuesto sin que lo pueda trasladar hacia otra persona $»^{20}$. Su ámbito de aplicación material es el territorio de la comunidad autónoma de Extremadura, como establece el artículo 2 de la norma legal.

Es importante destacar el contenido del artículo número 3, referido al hecho imponible del IDEC. Dicho precepto establece que «constituye el hecho imponible del Impuesto sobre los Depósitos de las Entidades de Crédito la captación de fondos de terceros, cualquiera que sea su naturaleza jurídica, por parte de las entidades mencionadas en el artículo 5 de esta Ley, y que comporten la obligación de restitución».

Los sujetos pasivos del impuesto son las entidades de crédito, por los fondos captados por su casa central y sus sucursales que estén situadas en territorio de la Comunidad Autónoma de Extremadura. Además, «la definición del hecho imponible de completa con el contenido del artículo número 4 donde se recoge la norma de exención del impuesto, tratándose esa norma de una codefinición del tributo» ${ }^{21}$. En función de lo anterior, el artículo 4 de la Ley establece que «gozarán de exención subjetiva el Banco de España y las autoridades de regulación monetaria, en cuanto tales, el Banco Europeo de Inversiones y las secciones de crédito de las cooperativas».

La base imponible ${ }^{22}$ del impuesto estará representada como establece el artículo 6 de la norma analizada, por la cuantía económica total, en términos de fondos, calculada promediando aritméticamente los saldos finales de cada trimestre natural de cada año de la suma de los epígrafes del Balance Reservado de las Entidades de Crédito siguientes:

\section{Acreedores. Administraciones Públicas españolas.}

Acreedores. Otros sectores residentes.

Acreedores. No residentes.

La cuota tributaria ${ }^{23}$ del impuesto resultará de aplicar un porcentaje a la base imponible en función de la cantidad, porcentaje que mínimo de un

${ }^{20}$ MERINO JARA, Isaac y otros, op.cit., 94.

${ }^{21}$ Galapero Flores, Rosa, op.cit., 92.

22 Vid., artículo 50 LGT: «La base imponible es la magnitud dineraria o de otra naturaleza que resulta de la medición o valoración del hecho imponible».

${ }^{23}$ Vid., artículo 56 LGT: «1. La cuota íntegra se determinará: a) Aplicando el tipo de gravamen a la base liquidable. b) Según cantidad fija señalada al efecto. 2. Para el cálculo 
$0.3 \%$ cuando la base resulte de 150.000 euros, y máximo de $0,5 \%$ cuando la base sea de 2.250.000 en adelante. A la cantidad resultante habrá que aplicarle una serie de deducciones previstas en la norma: a) 200.000 euros cuando la casa central y los servicios generales de la entidad de crédito estén efectivamente radicados en Extremadura, b) 5.000 euros por cada sucursal. Esta cantidad se elevará a 7.500 euros cuando la sucursal esté radicada en municipios cuya población de derecho sea inferior a 2.000 habitantes, y c) serán igualmente deducibles aquellas inversiones que siendo de utilidad pública o interés social para la región se concierten y aprueben con la Consejería de la Junta de Extremadura competente en Política Financiera. Las sumas de las deducciones tendrán, como límite, la reducción a cero los resultados negativos.

La última deducción anterior, referida a las inversiones en fines de utilidad social por parte de las entidades de crédito, ha sido objeto de numeroso debate doctrinal y jurisprudencial. En efecto, parte de la doctrina considera que este impuesto tiene una finalidad de carácter extrafiscal, posibilidad que puede acaecer aunque un tributo tenga una clara finalidad fiscal, debido a «que los tributos tienen hoy en el Estado moderno una finalidad esencialmente financiera, sin perjuicio de que al mismo tiempo puedan contribuir a otros objetivos. En consecuencia, todo tributo puede tener una finalidad fiscal y otra de carácter extrafiscal $»^{24}$. El carácter extrafiscal del impuesto se establece en el IDEC «mediante el sistema de deducciones a las inversiones de utilidad pública o interés social de los sujetos pasivos en la comunidad autónoma de Extremadura, propugnando que los obligados tributarios cambien su comportamiento (...) en términos matemáticos, se coloca al sujeto pasivo en la tesitura de decidir si acometer ese compromiso con el entorno voluntariamente en una determinada cantidad y en los sectores aludidos, o bien soportar el impuesto y que sea la administración la que destine lo recaudado

de la cuota íntegra podrán utilizarse los métodos de determinación previstos en el apartado 2 del artículo 50 de esta ley. 3. La cuota íntegra deberá reducirse de oficio cuando de la aplicación de los tipos de gravamen resulte que a un incremento de la base corresponde una porción de cuota superior a dicho incremento. La reducción deberá comprender al menos dicho exceso. Se exceptúan de esta regla los casos en que la deuda tributaria deba pagarse por medio de efectos timbrados. 4. El importe de la cuota íntegra podrá modificarse mediante la aplicación de las reducciones o límites que la ley de cada tributo establezca en cada caso. 5. La cuota líquida será el resultado de aplicar sobre la cuota íntegra las deducciones, bonificaciones, adiciones o coeficientes previstos, en su caso, en la ley de cada tributo. 6. La cuota diferencial será el resultado de minorar la cuota líquida en el importe de las deducciones, pagos fraccionados, retenciones, ingresos a cuenta y cuotas, conforme a la normativa de cada tributo.

${ }^{24}$ Calvo Ortega, Rafael, Curso de Derecho Financiero. Tomo I. Derecho Tributario (Madrid: editorial Thomson Civitas, 2009), 255. 
al sostenimiento de los gastos públicos según su público criterio» ${ }^{25}$. Además, se debe recordar que como ha establecido el Tribunal Constitucional, lo más probable es que los efectos extrafiscales se establezcan en un impuesto que también contiene un fin fiscal, así «difícilmente habrá impuestos extrafiscales químicamente puros, ya que resulta evidente que todos los impuestos sin excepción producen otros efectos, además de la recaudación de ingresos» ${ }^{26}$.

Alguna otra controversia podría plantearse en relación al artículo 149.1. 11. a de la Constitución Española que establece que las divisas, cambio y convertibilidad; bases de la ordenación de crédito, banca y seguros, son materias exclusivas del Estado, pero algún autor destacado considera que «lo que se pretende realmente es contribuir al fomento del desarrollo económico de la región extremeña, sin afectar en modo alguno, a las bases de la ordenación del crédito, banca, y seguros reservadas al Estado, puesto que ninguna modificación se produce en ellas como consecuencia de la implantación de esta medida tributaria $\gg^{27}$.

Las controversias jurisprudenciales derivadas del IDEC Extremeño serán objeto de análisis en el siguiente apartado, donde se analizará pormenorizadamente la sentencia del Tribunal Constitucional número 210/2012 de 14 de noviembre.

\section{EL ENJUICIAMIENTO AL IDEC EXTREMEÑO}

\section{A) Recurso de inconstitucionalidad}

Contra la Ley de la Asamblea de Extremadura 14/2001, de 29 de noviembre de 2001, reguladora del impuesto sobre depósitos de las entidades de crédito se interpone por parte del Estado Español recurso de inconstitucionalidad, dando lugar a un pronunciamiento del Tribunal Constitucional sobre la legalidad del IDEC, en su sentencia número 210/2012 de 14 de Noviembre.

Tres fueron los motivos de inconstitucionalidad que el abogado del estado alegó en su escrito de demanda:

a) En primer lugar, el abogado del estado alega que el impuesto sobre depósitos de las entidades de crédito grava un hecho imponible sujeto

25 JOVER Lorente, José Manuel, «La responsabilidad social corporativa como fin ultrafiscal subyacente del impuesto extremeño sobre los depósitos de las entidades de crédito», Impuestos. Revista de Doctrina, Legislación y Jurisprudencia 19, Octubre (2012): 104-105.

${ }^{26}$ Sentencia del Tribunal Constitucional 53/2014, de 10 de abril, fundamento jurídico sexto.

27 Checa González, Clemente, Los impuestos de las Comunidades Autónomas (Madrid: editorial Aranzadi, 2002), 356. 
al impuesto sobre el valor añadido, es decir, el IVA, contraviniendo por tanto el artículo 6.2 de la Ley Orgánica de financiación de las Comunidades Autónomas.

El citado artículo anteriormente explicado en el presente trabajo, prohíbe a las comunidades autónomas gravar hechos imponibles que ya estuvieran gravados por parte del Estado. En este caso, el abogado del estado considera que «pese a la diferente redacción de la norma extremeña y la estatal, el hecho imponible de ambos tributos es en realidad el mismo (...) lo verdaderamente gravado por el impuesto de Extremadura no es la actividad de captación de fondos sino los depósitos constituidos con los fondos captados» ${ }^{28}$. Si lo realmente captado por este impuesto son los depósitos constituidos, se produciría un supuesto de doble imposición con el impuesto sobre el valor añadido, ya que el artículo 11.2.12 de la Ley 37/1992, de 28 de diciembre, del impuesto sobre el valor añadido ${ }^{29}$ (en acrónimo LIVA), establece que el hecho imponible del IVA alcanza a los depósitos, que además, se encuentran exentos.

b) El segundo motivo de inconstitucionalidad aducido es que la regulación del IDEC es también contraria al artículo 6.3 de la LOFCA, ya que a juicio del abogado del estado, incide sobre una materia que se encuentra reservada a los entes locales.

Se afirma la coincidencia con el Impuesto de actividades económicas (en acrónimo IAE), debido a que al tratarse el IDEC de un tributo directo, donde se prohíbe su repercusión a terceros, el impuesto recae sobre la misma manifestación de riqueza que el IAE, debido a que la actividad de las instituciones financieras se encuentran dentro del Decreto Legislativo 1175/1990, de 28 de septiembre por el que se aprueban las tarifas y la instrucción del impuesto sobre actividades económicas ${ }^{30}$.

c) El tercer y último motivo de inconstitucionalidad que alega el abogado del estado, es la infracción del principio de territorialidad de las competencias, consagrados en los artículos 139.2 y 157.2 de la Constitución Española, y los artículos 9 b) y 9 c) de la LOFCA.

${ }^{28}$ Sentencia del Tribunal Constitucional número 210/2012 de 14 de noviembre, página 2.

${ }^{29}$ Ley 37/1992, de 28 de diciembre, del Impuesto sobre el Valor Añadido, «BOE» núm. 312, de 29 de diciembre de 1992.

${ }^{30}$ Real Decreto Legislativo 1175/1990, de 28 de septiembre, por el que se aprueban las tarifas y la instrucción del Impuesto sobre Actividades Económicas, «BOE» núm. 234, de 29 de septiembre de 1990. 
Dicho principio, territorialidad, ya ha sido expuesto en la parte introductoria del presente trabajo, basándose fundamentalmente, en la necesidad de que un tributo autonómico solo puede gravar hechos imponibles que ocurran dentro de su territorio, y además, no puede adoptar medidas que supongan un obstáculo para la libre circulación de empresas y de capitales. Respecto a la primera cuestión, el abogado del estado considera en su escrito de demanda que «aunque el objeto de gravamen sean los fondos captados por las entidades domiciliadas en la comunidad autónoma de Extremadura, no se excluye que los depositantes de dichos fondos se encuentran fuera de esta comunidad 0 incluso fuera de España $\rangle^{31}$.

En relación a la libre circulación de empresas y de capitales, el abogado considera que «esta vulneración se atribuye concretamente al artículo 7.3 de la Ley del IDEC, que establece una deducción en la cuota por inversiones de utilidad pública o de interés social en la región $»^{32}$.

Estos son los motivos, por los que se alegó ante el Tribunal Constitucional la ilegalidad del impuesto sobre depósitos de las entidades de crédito creado por la comunidad autónoma de Extremadura. El Tribunal en su sentencia, desmonta uno a uno los tres argumentos anteriores, considerando como se verá más tarde, que el impuesto Extremeño es perfectamente legal y constitucional.

\section{B) Análisis de la Sentencia del Tribunal Constitucional número 210/2012 de 14 de noviembre}

La estructura que siguió el Tribunal Constitucional Español es exactamente igual, a la formulada anteriormente por el abogado del estado, es decir, su fallo se divide en los mismos tres apartados:

a) Vulneración del artículo 6.2 de la LOFCA, debido a la posible contradicción del IDEC con el impuesto sobre el valor añadido estatal.

El abogado del estado, alegaba que el hecho imponible del IDEC autonómico, era el mismo que el del IVA estatal, cuestión que desmontó el Tribunal en su fallo, con los siguientes razonamientos. En efecto, para el Alto Tribunal, «para determinar si se han vulnerado las prohibiciones de doble imposición contenidas en el artículo 6.2 LOFCA, el examen de los tributos que se reputan coincidentes no puede ceñirse a la mera comparación de la definición legal de sus hechos imponibles, debiendo abarcar también los restantes

${ }^{31}$ Sentencia del Tribunal Constitucional número 210/2012 de 14 de noviembre, página 3.

${ }^{32}$ Ibidem. 
elementos del tributo que se encuentran conectados con el hecho imponibles $\rangle^{33}$.

En atención a lo anterior, el Alto Tribunal se encarga de describir exhaustivamente todos los elementos del tributo autonómico (base imponible, cuota tributaria, cuota íntegra, deducciones y periodo impositivo) expresados, ya en este trabajo anteriormente, para llegar a la siguiente conclusión, «los elementos de cuantificación del tributo permiten concluir que el objeto del gravamen del IDEC no es la actividad bancaria de captación en sí misma considerada, sino únicamente uno de sus resultados (el pasivo acumulado por la captación de depósitos). En consecuencia, el IDEC no recae sobre la realización de transacciones económicas, sino que grava el rendimiento que potencialmente se le presupone a los depósitos captados por las entidades bancarias, como elemento del pasivo susceptible de generar ingresos ${ }^{34}$.

El Tribunal Constitucional desestima este motivo de ilegalidad, ya que al tratarse la actividad principal del impuesto sobre depósitos de las entidades de crédito, la captación de fondos, y al ser la actividad principal del IVA la contraprestación pactada por las operaciones sujetas a su gravamen, no existe violación del artículo 6.2 de la Ley Orgánica de Financiación de las Comunidades Autónomas.

b) Vulneración del artículo 6.3 LOFCA, debido a la posible contradicción del IDEC con el impuesto sobre actividades económicas local.

El tribunal realiza exactamente la anterior operación realizada en el anterior apartado, comparando no solo los hechos imponibles de los citados impuestos, sino también los distintos elementos del tributo, para determinar si pudiera darse una violación en el sentido de una duplicidad, como establece el artículo 6.3 $\mathrm{LOFCA}^{35}$. En atención a esta actividad, la sentencia considera que «el IAE grava la mera actividad económica con independencia

${ }^{33}$ Sentencia del Tribunal Constitucional número 210/2012 de 14 de noviembre, página 10 .

34 Ibidem., página 11.

35 Debe recordarse que la Ley Orgánica 3/2009, de 18 de Diciembre, de modificación de la Ley Orgánica de financiación de las comunidades autónomas, «BOE» núm. 305, de 19 de diciembre de 2009, otorgó una nueva redacción a este precepto, la descrita en el presente trabajo, ya que la anterior redacción establecía que:«Las comunidades autónomas podrán establecer y gestionar tributos sobre las materias que la legislación de régimen local reserve a las corporaciones locales, en los supuestos en que dicha legislación lo prevea y en los términos que la misma contemple. En todo caso, deberán establecerse las medidas de compensación o coordinación adecuadas en favor de aquellas Corporaciones, de modo, que los ingresos de tales Corporaciones Locales no se vean mermados ni reducidos tampoco en sus posibilidades de crecimiento futuro». 
de su resultado, esto es, en el caso de las entidades financieras, se capten o n. $^{\circ}$ depósitos y con independencia de su cuantía (...), en cuando al impuesto sobre depósitos de entidades de crédito, el examen de sus elementos, permite concluir que lo que se sujeta a gravamen no es la mera actividad de captación o el mero ejercicio de una actividad crediticia, sino su resultado, de manera que se gravan los depósitos como elementos del pasivo bancario susceptible de generar riqueza $»^{36}$.

c) Vulneración de los artículos 139.2 y 157.2 CE y de los artículos 9 b) y c) $L O F C A$, debido a la posible afectación del IDEC a la libertad de circulación, como por poder incurrir en la prohibición de no gravar bienes extraterritoriales.

Dentro de este apartado, el tribunal realiza dos consideraciones diferentes.

En primer lugar, se ocupa de analizar los artículos $157.2 \mathrm{CE}^{37}$ y 9.b) de la LOFCA $^{38}$, analizados anteriormente en el presente trabajo. Estos artículos, impiden a las Comunidades Autónomas gravar negocios, actos o hechos celebrados o realizados fuera de su territorio. Para determinar si efectivamente, el IDEC gravaba actos que podrían ocurrir fuera de su territorio, gravando depósitos que se han constituido por personas físicas o jurídicas que residen fuera de Extremadura, como alegaba el abogado del estado, el Alto Tribunal analiza los puntos de conexión del tributo Extremeño.

Para analizar estos puntos de conexión, el Tribunal hace referencia al elemento territorial del impuesto (concretado en su artículo 5.1) que establece, como se analizó anteriormente en el presente trabajo, que el IDEC es un impuesto directo que grava la capacidad económica puesta de manifiesto por los depósitos bancarios que radiquen en la sucursales de las entidades bancarias situadas en su comunidad. En vista de lo anterior, el Tribunal razona que «no altera la legalidad del tributo el hecho de que los fondos

${ }^{36}$ Sentencia del Tribunal Constitucional número 210/2012 de 14 de noviembre, página 14.

37 Vid., artículo 157.2 CE: «Las Comunidades Autónomas no podrán en ningún caso adoptar medidas tributarias sobre bienes situados fuera de su territorio o que supongan obstáculo para la libre circulación de mercancías o servicios»».

38 Vid., artículo 9 b) LOFCA:»Las Comunidades Autónomas podrán establecer sus propios impuestos, respetando, además de lo establecido en el artículo sexto de esta Ley, los siguientes principios:

b) No podrán gravarse, como tales, negocios, actos o hechos celebrados o realizados fuera del territorio de la comunidad impositora, ni la transmisión o ejercicio de bienes, derechos y obligaciones que no hayan nacido ni hubieran de cumplirse en dicho territorio o cuyo adquirente no resida en el mismo. 
depositados en las entidades puedan eventualmente proceder de personas, físicas o jurídicas, que no residan en la Comunidad Autónoma, pues como ha quedado expuesto, el impuesto no grava transacciones económicas sino su resultado, por lo que el depositante es ajeno a la relación jurídico-tributaria del impuesto sobre depósitos de las entidades de crédito ${ }^{39}$.

En consecuencia, se desestimó la infracción de los artículos 157.2 CE y 9 b) LOFCA, ya que a juicio del Tribunal, el sujeto pasivo del impuesto, al ser las entidades bancarias, no se encuentran afectados, por la nacionalidad o vecindad de las personas que constituyan sus fondos en las mismas.

El segundo razonamiento del tribunal dentro de este apartado, pivota en relación a la infracción del artículo 139.2 de la Constitución Española ${ }^{40}$ y el artículo 9 c) de la Ley Orgánica de Financiación de las Comunidades Autónomas $^{41}$. En este apartado, el Tribunal analiza, si como aducía el Abogado del Estado, el establecimiento de un sistema de deducciones por la realización de ciertas actividades de carácter social para la comunidad autónomas, puede suponer una restricción a la libertad de decisión de las entidades de crédito en relación con la asignación de los depósitos captados. Estas deducciones podrían minorar el impuesto hasta convertirlo en cero, cuestión que alertaba al abogado del estado.

Para analizar esta cuestión, el Tribunal parte no solo de razonamientos propios, sino también de los pronunciamientos que el Tribunal de Justicia de la Unión Europea ha efectuado al respecto. Así, entre otras, hace mención a la sentencia de 25 de octubre de 2012, (Asunto C-387/11), Comisión Europea c. Reino de Bélgica, Reino Unido de Gran Bretaña, e Irlanda del Norte, que declara contraria a la libertad de establecimiento la normativa del Reino de Bélgica que suponía una imposición de los rendimientos de capitales y de bienes muebles distinta en función de que estos sean percibidos por sociedades de inversión belgas o extranjeras. El Tribunal Constitucional considera que «el fin último del artículo 9 c) LOFCA es la protección del mercado interior, lo que en materia tributaria impide en particular establecer medidas

39 Sentencia del Tribunal Constitucional número 210/2012 de 14 de noviembre, página 16.

40 Vid., artículo 139.2 CE:» Ninguna autoridad podrá adoptar medidas que directa o indirectamente obstaculicen la libertad de circulación y establecimiento de las personas y la libre circulación de bienes en todo el territorio español».

${ }^{41}$ Vid., artículo 9 c) LOFCA:» Las Comunidades Autónomas podrán establecer sus propios impuestos, respetando, además de lo establecido en el artículo sexto de esta Ley, los siguientes principios: No podrán suponer obstáculo para la libre circulación de personas, mercancías y servicios capitales, ni afectar de manera efectiva a la fijación de residencia de las personas o a la ubicación de Empresas y capitales dentro del territorio español, de acuerdo con lo establecido en el artículo segundo, uno, a), ni comportar cargas trasladables a otras Comunidades». 
que fragmenten dicho mercado estableciendo diferencias entre residentes y no residentes en una comunidad $»^{42}$.

El tribunal en función de la doctrina constitucional y del Tribunal de Justicia Europeo, considera que «la deducción (en actividades sociales de la comunidad de Extremadura) pretender incentivar inversiones, inversiones que son enteramente voluntarias, de forma que la única consecuencia que tiene para el contribuyente no realizar dichas inversiones es el pago íntegro, sin beneficios fiscales del tributo autonómico» ${ }^{43}$.

En vista de lo anterior, el Tribunal desestima el tercer motivo de ilegalidad estudiado, y declara la constitucionalidad del impuesto sobre depósitos de las entidades de crédito en la Comunidad Autónoma de Extremadura, regulado en la Ley de la Asamblea de Extremadura 14/2001 de 29 de noviembre, reguladora del impuesto sobre depósitos de las entidades de crédito.

\section{REACCIONES A LA DECLARACIÓN DE CONSTITUCIONALIDAD DEL IDEC EXTREMEÑO}

\section{A) La reacción del Estado Español}

Una vez se publicó el fallo del Tribunal Constitucional declarando legal el impuesto sobre depósitos de entidades de crédito Extremeño, se publicaron un sinfín de reacciones, de sentido positivo en algunos casos y de sentido negativo en otros. Desde un punto de vista positivo, existen autores que consideran que «el hecho de gravar a las entidades de crédito con el IDEC, no es arbitrario ni tampoco irracional, ya que la desigualdad legalmente introducida a través de la Ley de este impuesto no carece de justificaciones plausibles a la vista del gran aumento de los beneficios de las entidades crediticias que se ha producido en los últimos años, siendo por ello lógico que las mismas cooperan en mayor medida que la que lo vienen haciendo hasta el presente al desarrollo económico» ${ }^{44}$. Por el contrario, parte de la doctrina se encuentra en contra del pronunciamiento del Alto Tribunal, existiendo autores que consideran cuestiones como «no puede estarse de acuerdo con la Sentencia del Tribunal Constitucional, ya que su doctrina es demasiado

${ }^{42}$ Sentencia del Tribunal Constitucional número 210/2012 de 14 de noviembre, página 17.

43 Ibidem., página 18.

${ }^{44}$ Galapero Flores, Rosa, «El impuesto sobre los depósitos de las entidades de crédito de la comunidad autónoma de Extremadura. La declaración de su constitucionalidad por el Tribunal Constitucional», en Impuestos. Revista de Doctrina, Legislación y Jurisprudencia 6, Sección Divulgación, Junio (2013): 93. 
simplista en cuanto a los conceptos generales del Derecho Financiero y Tributario Español y al análisis de la incidencia del IDEC en las libertades de circulación comunitarias, particularmente, las relativas al establecimiento de actividades y a la libre circulación de capitales $\rangle^{45}$, y otros, en la misma línea «el tributo debió haberse declarado inconstitucional, y como no se ha hecho, es urgente modificar la LOFCA para recoger expresamente la prohibición de tributos de este tipo, y en general de tributos basados sobre la renta de las sociedades o cualquier indicador directo o indirecto de la misma $\rangle^{46}$.

Además de posturas a favor y en contra de la citada sentencia, existen autores que encuentran dudas sobre la constitucionalidad respecto a otras figuras no incluidas en el análisis de la sentencia, como pudiera ser el Impuesto sobre sociedades, de suerte tal, que «el IDEC constituye una tipología de imposición regional sobre los elementos de producción que revela graves problemas de constitucionalidad, al suponer una modalidad de tributación sobre una manifestación potencial de riqueza y por gravar un elemento de producción de la actividad financiera como el pasivo captado de terceros, que ya se sujeta a imposición en el hecho imponible del impuesto sobre sociedades $\rangle^{47}$.

Parece claro a la vista de lo anterior, que son más los autores que se olvidan de las actividades poco éticas realizadas durante muchos años en España, que han llevado al sector a su dependencia económica, siendo necesario rescatar por parte de Europa al mismo, y la posibilidad que existe a través de esta figura, de hacer colaborar a las entidades de crédito con el sostenimiento de los gastos públicos y del estado de bienestar. Ahora bien, este ataque de olvido, no solo se encuentra en la doctrina tributaria y financiera, sino también, en el propio Estado Español. En efecto, el gobierno de España, reacciona de una manera acelerada al fallo del Tribunal Constitucional, por el que se declara constitucional el IDEC extremeño, creando un impuesto sobre los depósitos de entidades de crédito estatal, una figura muy controvertida, como después se analizará, utilizando para ello una ley ordinaria, la Ley 16/2012, de 27 de diciembre, por la que se adoptan diversas medidas tributarias dirigidas a la consolidación de las finanzas públicas y al impulso de la actividad económica ${ }^{48}$, concretamente a través de su artículo 19.

${ }^{45}$ Cruz Amorós, Miguel, Esquivel Fernández, Ariane, «El impuesto extremeño sobre depósitos de las entidades de crédito», Diario La Ley 3159 (2013), 2.

${ }^{46}$ FAlCón y Tella, Ramón, «El impuesto sobre los depósitos de las entidades de crédito: sobre la necesidad de un nuevo modelo para articular la potestad tributaria estatal y autonómica», Revista Quincena Fiscal 20 (2013), 4.

47 García NovoA, César, «El futuro de la fiscalidad autonómica sobre los depósitos bancarios», Revista catalana de dret púbic 46 (2013), 121.

${ }^{48}$ Ley 16/2012, de 27 de diciembre, por la que se adoptan diversas medidas tributarias dirigidas a la consolidación de las finanzas públicas y al impulso de la actividad económica, «BOE» núm. 312, de 28 de diciembre de 2012. 
Analizando la estructura del impuesto estatal se puede observar como el mismo, se encuentra configurado exactamente en los mismos términos que el IDEC extremeño, pero con una salvedad, el tipo de gravamen se fija en el cero por ciento. En efecto, el IDEC estatal, se encuentra configurado como un tributo de carácter directo, aplicable en todo el territorio Español, y que obliga a sus contribuyentes (las entidades de crédito sitas en España), a pagar un tributo debido a la captación de fondos de terceros con obligación de restitución de los mismos. La Ley no establece deducciones, cuestión que llama la atención a algún autor, que expresa «falta en esta ley la posibilidad de establecer deducciones, algo característico de las normativas autonomías, como instrumento de desarrollo socioeconómico regional, un objetivo, el de la extrafiscalidad, que ha sido destacado por el TC, y que resultaba una característica esencial del IDEC autonómico» ${ }^{49}$. Pero, la principal controversia, aparte de no establecer deducciones en el impuesto, cuestión característica del IDEC extremeño, es la imposición de un tipo de gravamen cero, ya que, con esta imposición, no se recaudará nada con la creación de este tributo, entonces al presente autor, le surge una cuestión, ¿Cuál es el fin de la creación de este impuesto por parte del Estado Español?

La respuesta a esta cuestión aparece dada por numerosos autores y todos apuntan a una misma dirección, así se considera que «el único efecto que se pretende conseguir con el nuevo impuesto es excluir la posibilidad de impuestos autonómicos similares ${ }^{50}$, y en el mismo sentido, otros autores establecen que «la Ley 16/2012 menoscaba clarísimamente el poder tributario de los Entes territoriales y, con ello, su autonomía financiera, con la finalidad encubierta y evidente, de satisfacer las demandas de las entidades financieras ${ }^{51}$. En vista de lo anterior, parece claro que la intención del Estado Español, al establecer este tributo propio es cohibir la posibilidad de las comunidades autónomas de gravar estos hechos imponibles, por más que en la exposición de motivos de la Ley 16/2012, intente justificar su creación con motivos vanos como «se crea el Impuesto sobre los Depósitos en las Entidades de Crédito con la pretensión de asegurar un tratamiento fiscal armonizado que garantice una mayor eficiencia en el funcionamiento del sistema financiero»».

El motivo por el cual los principales autores consideran que el único efecto de la creación de esta figura es eliminar los impuestos autonómicos

49 PÉreZ ZúÑIGA, José María, «El impuesto estatal sobre depósitos en entidades de crédito», Actualidad Administrativa 6 (2013), 3.

${ }^{50}$ García Novoa, César, op.cit., 132.

51 Mata Sierra, María, CARbajo Nogal, Carlos, «Conflictos entre la Hacienda estatal y las autonómicas en el Impuesto sobre los depósitos de las entidades de crédito», Revista Quincena Fiscal 18 (2013), 2. 
sobre los depósitos de entidades de crédito, es la previsión ya citada en numerosas ocasiones en el presente trabajo, contenida en el artículo 6.2 de la Ley Orgánica de Financiación de las Comunidades Autónomas. En efecto, este precepto establece que las comunidades autónomas no podrán gravar hechos imponibles que ya se encuentren gravados por el estado, cuestión que impide por tanto, desde la promulgación de la Ley 16/2012, de 27 de diciembre, a nuevas comunidades autónomas, que no tuvieran un impuesto similar, crear el mismo, ya que se incurriría en un supuesto de doble imposición no permitido por la LOFCA. Ahora bien, es necesario destacar la segunda parte del precepto en cuestión, ya que el mismo establece «cuando el Estado, en el ejercicio de su potestad tributaria originaria establezca tributos sobre hechos imponibles gravados por las Comunidades Autónomas, que supongan a éstas una disminución de ingresos, instrumentará las medidas de compensación o coordinación adecuadas en favor de las mismas».

En función de lo anterior, el Gobierno tiene la obligación de resarcir a todas las comunidades autónomas que antes de la promulgación del IDEC Estatal, tuvieran en vigor un impuesto de similares características en su comunidad autónoma. Ahora bien, ¿Cuántas comunidades autónomas tenían un tributo de estas características?, ¿Solo Extremadura? La respuesta debe ser necesariamente negativa. En efecto, la Ley 16/2012, de 27 de diciembre, en su artículo 19 establece que existirá obligación de resarcir a aquellas comunidades autónomas que tuvieran creado un IDEC con anterioridad al 1 de diciembre de $2012^{52}$. Estas comunidades eran: Extremadura, Andalucía y Canarias. Dejando a un lado el IDEC Extremeño, ya analizado con detalle, toca exponer las iniciativas autonómicas del resto de comunidades.

\section{B) La respuesta autonómica}

La comunidad Autónoma de Andalucía creó el impuesto sobre depósitos de clientes de entidades de crédito, a través de la Ley 11/2010, de 3 de diciembre, de medidas fiscales para la reducción del déficit público y para la sostenibilidad $^{53}$, concretamente a través de su artículo número 6. Este

52 Artículo 19 de la Ley 16/2012, de 27 de diciembre: «La medida en que el impuesto que establece esta Ley recaiga sobre hechos imponibles gravados por las Comunidades Autónomas y esto produzca una disminución de sus ingresos, será de aplicación lo dispuesto en el artículo 6.2 de la Ley Orgánica 8/1980, de 22 de septiembre, de Financiación de las Comunidades Autónomas. Lo dispuesto en el párrafo anterior será únicamente de aplicación respecto de aquellos tributos propios de las Comunidades Autónomas establecidos en una Ley aprobada con anterioridad a 1 de diciembre de 2012».

${ }^{53}$ Ley 11/2010, de 3 de diciembre, de medidas fiscales para la reducción del déficit público y para la sostenibilidad, «BOJA», núm.243, de 15 de diciembre de 2010. 
impuesto entraría en vigor a partir del 1 de enero de 2011, y solo en su primer año, el ejecutivo andaluz tenía previsto recaudar 132 millones de Euros, aplicando los siguientes tipos de gravamen: a) $0,3 \%$ sobre bases imponibles iguales o inferiores a 150.000 euros, b) $0,4 \%$ sobre bases imponibles comprendidas entre 150.000 y 450.000 euros, y c) $0.5 \%$ sobre bases imponibles iguales o superiores a 600.000 . Este tributo nunca fue objeto de recurso de inconstitucionalidad por parte del Estado, ya que en los términos que se encontraba formulado, era idéntico al IDEC Extremeño, por lo que el fallo del Tribunal Constitucional, por el que lo declaró constitucional, afectaba también al IDEC Andaluz.

La comunidad autónoma de Canarias crea el Impuesto sobre Depósitos de Clientes en las entidades de Crédito, mediante la Ley 4/2012, de 25 de Junio de medidas administrativas y fiscales ${ }^{54}$, que entra en vigor el 1 de Julio de 2012, concretamente a través de su artículo número 41. Este tributo, tiene exactamente los mismos tipos de gravamen que el caso de Andalucía.

Por tanto, las comunidades autónomas que serán compensadas por la vía del artículo 6.2 LOFCA son solo tres: Extremadura, Andalucía y Canarias. Este hecho, también ha producido una numerosa polémica tanto doctrinal, como a nivel territorial. En primer lugar, existen autores que se encuentran radicalmente en contra de este sistema de compensación solo a unas determinas comunidades autónomas, así consideran que «lo que hay que compensar es la perdida de fuentes posibles de gravamen, es decir, la perdida en favor de la Hacienda Estatal de objetos susceptibles de ser gravados por las Comunidades Autónomas, con independencia de que existiera o no efectivamente un tributo autonómico y de la recaudación derivada del mismo. Si no se hace así, se estará incitando a las comunidades a establecer impuestos absurdos con la finalidad de que el Estado apruebe un tipo cero y les compense, con el consiguiente daño para los contribuyentes que tenga que soportar el impuesto mientras eso sucede, y con el resultado de una distribución de la recaudación arbitraria e injusta» ${ }^{55}$, y en el mismo sentido, «la situación no puede ser más injusta en términos objetivos, ya que se favorece a las comunidades más activas en la creación de tributos propios, perjudicando a las más moderadas $\rangle^{56}$.

Ahora bien, la polémica sobre la compensación prevista en este tributo, no se agota aquí, sino que tiene otro capítulo importante, protagonizado especialmente por la comunidad autónoma de Cataluña, y con la colaboración de la comunidad autónoma Valenciana y Asturiana. En efecto, estas tres comunidades, deciden crear un impuesto autonómico sobre depósitos de las

${ }^{54}$ Ley 4/2012, de 25 de Junio de medidas administrativas y fiscales, «BOE» núm. 166, de 12 de julio de 2012 .

${ }^{55}$ FAlCón y Tella, Ramón, op.cit., 6.

${ }^{56}$ García Novoa, César, op.cit., 132. 
entidades de créditos, después de que el Estado hubiera creado el suyo, vulnerando el articulo 6.2 LOFCA, y provocando recursos de inconstitucionalidad contra sus tributos. Pero, el caso mas llamativo, es el caso de Cataluña.

La comunidad autónoma de Cataluña, tramita la creación del impuesto sobre depósitos de clientes de entidades de crédito a la par que el ejecutivo Estatal estaba realizando su Ley 16/2012, con la única intención de sacar a la luz este tributo, y obtener la compensación establecida en el artículo 6.2 LOFCA. Pero, la estrategia Catalana no resulta como se había previsto, ya que, su Decreto Ley 5/2012 de 18 de diciembre de $2012^{57}$ por el que se aprueba este tributo, es excluido del ámbito de aplicación de la compensación del tributo estatal por parte del Gobierno Español. Este tributo autonómico establecía los mismos tipos impositivos que el caso Andaluz y Canario, y por él se esperaba recaudar más de 500 millones de euros anuales. Aparte de no proceder a su compensación, el Estado Español interpuso un recurso de inconstitucionalidad el 15 de Enero de 2013 contra el citado Decreto Ley, y por su parte la comunidad autónoma de Cataluña, interpuso un recurso de inconstitucionalidad contra el artículo 19 de la Ley 16/2012, por la que se aprueba el impuesto estatal, que será objeto de análisis en el siguiente apartado del presente trabajo. El Tribunal Constitucional declaró inconstitucional la norma autonómica en su sentencia número 107/2015 de 28 mayo $^{58}$.

La comunidad Autónoma de Asturias creó el impuesto sobre depósitos de entidades de crédito a través de la Ley de presupuestos generales para Asturias de $2013^{59}$, concretamente a través de su artículo 41 . La intención de la comunidad autónoma de Asturias es intentar acceder al sistema de compensación, al igual que el caso Catalán, sirviéndose para ello de un instrumento que revierte serias dudas de inconstitucionalidad como es una ley de presupuestos generales, ya que el artículo $134.7 \mathrm{CE}^{60}$ prohíbe expresamente esta cuestión. Posteriormente, incluye la regulación de este impuesto en los artículos 52 a 68 del Decreto Legislativo 1/2014, de 23 de Julio por el que aprueba el texto refundido de las disposiciones leales del Principado de

${ }^{57}$ Decreto Ley 5/2012 de 18 de diciembre de 2012, «DOGC» núm. 6277, de 19 de diciembre de 2012.

58 Sentencia del Tribunal Constitucional número 107/2015 de 28 mayo, fundamento jurídico tercero:» A la vista del incumplimiento de lo establecido en el art. 203.5 EAC cabe concluir, sin necesidad de proyectar sobre este asunto nuestra doctrina relativa a los límites formales y materiales derivados del art. 86.1 CE, que el Decreto-ley 5/2012, de 18 de noviembre, es inconstitucional y nulo. Alcanzada esta conclusión, resulta innecesario el enjuiciamiento de los motivos impugnatorios restantes.

${ }_{59}$ Ley de presupuestos generales para Asturias de 2013, «BOPA», núm. 300, de 29 de diciembre de 2012.

60 Artículo 134.7 CE: «La Ley de Presupuestos no puede crear tributos. Podrá modificarlos cuando una ley tributaria sustantiva así lo prevea». 
Asturias en materia de tributos propios ${ }^{61} \mathrm{Al}$ igual que el caso Catalán, el Estado recurre por inconstitucionalidad esta Ley, siendo declarado inconstitucional por el Tribunal Constitucional en su sentencia número 202/2015 de 24 de Septiembre ${ }^{62}$. El ejecutivo Asturiano, decide también recurrir al Constitucional la Ley 16/2012 del Estado Español.

El último caso, es el de la comunidad autónoma Valenciana. Esta comunidad creó el impuesto sobre depósitos de entidades de crédito a través del artículo 161 de la Ley 5/2013, de 23 de diciembre, de medidas fiscales, de gestión administrativa y financiera y de organización de la Generalitat ${ }^{63}$, el cual fue recurrido por el Estado ante el Tribunal Constitucional por vulnerar el artículo 6.2 LOFCA. El Tribunal Constitucional declaró inconstitucional el precepto anteriormente citado en su sentencia número 30/2015 de 19 de febrero ${ }^{64}$.

Siguiendo con la cuestión sobre la compensación, se debe destacar que el Consejo de Ministros el 26 de abril de 2013, anunció una modificación del tipo de gravamen del impuesto del cero por ciento, al 2 por mil, que «servirá para compensar a las tres comunidades autónomas que lo han tenido vigente y cuya vigencia queda anulada a partir de la existencia del impuesto estatal $\rangle^{65}$.

Hasta aquí, el análisis de la problemática de la compensación acerca de la Ley 16/2012 del Estado Español, pero esta no era su única fuente de discusión. Anteriormente, ya se expuso que una de sus principales cabezas de batalla era la inclusión de un tipo de gravamen cero, provocando una enorme discusión doctrinal y legal. Pues bien, aparte de estas dos cuestiones controvertidas, existe una que reviste ciertas notas de importancia, como es, el sistema utilizado por el gobierno Estatal para crear el impuesto sobre depósitos de entidades de crédito. El gobierno utilizó una ley orgánica, cuestión que

${ }^{61}$ Decreto Legislativo $1 / 2014$, de 23 de Julio por el que aprueba el texto refundido de las disposiciones leales del Principado de Asturias en materia de tributos propios, «BOPA» núm. 175, de 29 de julio de 2014.

${ }^{62}$ Sentencia del Tribunal Constitucional número 202/2015 de 24 de Septiembre, fundamento jurídico sexto: «un estudio de los elementos esenciales del tributo, permite concluir que se trata sustancialmente similar al impuesto estatal sobre depósitos, incurriendo en la incompatibilidad que establece el artículo 6.2 LOFCA».

${ }^{63}$ Ley $5 / 2013$, de 23 de diciembre, de medidas fiscales, de gestión administrativa y financiera y de organización de la Generalitat, «DOCV» núm. 7181 de 27 de Diciembre de 2013.

${ }^{64}$ Sentencia del Tribunal Constitucional número 30/2015 de 19 de febrero, fundamento jurídico cuarto: «de acuerdo con nuestra doctrina, los elementos esenciales de la regulación del IDEC Valenciano en comparación con los del IDEC Estatal, suponen una vulneración de los artículos 133.2 y 157.3 CE, así como del articulo 6.2 LOFCA, por lo que debe declararse la inconstitucionalidad y nulidad del artículo 161 de la Ley de las Cortes Valencianas 5/2013, de 23 de diciembre».

${ }_{65}$ Diario de Sesiones, Congreso de los Diputados, Pleno y Diputación Permanente, núm. 99, de 20 de abril de 2013. 
puede chocar con los mandatos del artículo $157 \mathrm{CE}^{66}$, especialmente su punto primero y tercero. Así existen autores que consideran «estamos ante un ejercicio torticero del poder tributario del Estado, que podría incluso calificarse de fraudulento. La creación de un impuesto sin la más mínima pretensión recaudatoria y limitado a ocupar un hecho imponible para vetar su previsión por las leyes autonómicas supone afectar al poder tributario de las comunidades autónomas mediante ley ordinaria, lo que supone una frontal vulneración del artículo 157. 3 de la Constitución» ${ }^{67}$.

Por todos estos motivos, las comunidades autónomas de Cataluña y Asturias, decidieron recurrir esta Ley ante el Tribunal Constitucional. El fallo del Alto Tribunal será objeto de análisis en el siguiente apartado del presente trabajo.

\section{ANÁLISIS DE LA SENTENCIA DEL TRIBUNAL CONSTITUCIONAL NÚMERO 26/2015 DE 19 DE FEBRERO}

Esta sentencia resuelve las dudas acerca de la constitucionalidad o $\mathrm{n} .^{\circ}$ del artículo 19 de la Ley 16/2012, de 27 de diciembre, por la que se adoptan diversas medidas tributarias dirigidas a la consolidación de las finanzas públicas y al impulso de la actividad económica mediante el que se crea el impuesto sobre depósitos de las entidades de crédito.

Este impuesto es recurrido por parte del Gobierno de la Comunidad Autónoma de Cataluña, en base a los siguientes motivos:

a) En primer lugar, el Gobierno autonómico alega que el IDEC es en realidad una simulación de impuesto, ya que al tener un tipo cero, resulta contrario al artículo $31 \mathrm{CE}^{68}$, ya que la finalidad de obtener ingresos es definitoria del concepto de tributo. En consecuencia, su creación no puede ampararse en las competencias para crear tributos.

${ }^{66}$ Artículo 157 CE: «1. Los recursos de las Comunidades Autónomas estarán constituidos por: a) Impuestos cedidos total o parcialmente por el Estado; recargos sobre impuestos estatales y otras participaciones en los ingresos del Estado. b) Sus propios impuestos, tasas y contribuciones especiales.

3. Mediante ley orgánica podrá regularse el ejercicio de las competencias financieras enumeradas en el precedente apartado 1, las normas para resolver los conflictos que pudieran surgir y las posibles formas de colaboración financiera entre las Comunidades Autónomas y el Estado.

${ }^{67}$ Garcia Novoa, César, op.cit., 133.

68 Vid., artículo $31 \mathrm{CE}$ : «Todos contribuirán al sostenimiento de los gastos públicos de acuerdo con su capacidad económica mediante un sistema tributario justo inspirado en los principios de igualdad y progresividad que, en ningún caso, tendrá alcance confiscatorio»». 
b) En segundo lugar, se considera que el modo de aprobación del impuesto no es el adecuado, ya que el artículo 157.3 CE exige la presencia de una ley orgánica. Esta norma, según el ejecutivo autonómico sería la LOFCA.

c) El tercer motivo de la supuesta inconstitucionalidad, se dirige contra el sistema de compensación previsto en la norma, es decir, contra la negativa del Estado de compensar a todas las comunidades autónomas, y no solo a Extremadura, Andalucía y Canarias.

El Tribunal Constitucional analiza todos los puntos planteados por las partes en el proceso, y emite su sentencia, siguiendo exactamente la misma estructura que la planteada anteriormente:

a) Posible infracción del artículo $31 \mathrm{CE}$, con la consiguiente inaplicación del marco competencial vigente, establecido en los artícu$\operatorname{los} 133.1 \mathrm{CE}^{69}$ y $149.1 .14 .{ }^{\mathrm{a}} \mathrm{CE}^{70}$.

El tribunal parte de la noción de tributo para poder analizar dicho apartado, poniendo de manifesto, como no podría ser de otra forma, que «uno de los elementos centrales de la noción de tributo es su finalidad recaudatoria, $o$ lo que es lo mismo, allegar recursos a la Hacienda Pública, inherente a la propia función de sostener la financiación del gasto público a que se refiere el artículo $31.1 \mathrm{CE} \gg^{71}$. Ahora bien, como se introdujo en los anteriores epígrafes del presente trabajo, la finalidad fiscal no es la única exclusiva de un tributo, sino que el mismo puede poseer también una determinada función extrafiscal. Para el Alto Tribunal, «no toda fuente de capacidad económica debe ser objeto de gravamen (...), ya que, el legislador puede declarar la exoneración de determinadas rentas cuando exista la oportuna justificación, y siempre que ello no suponga el desconocimiento de los límites al ejercicio del poder tributario que se deriven de los principios constitucionales contenidos en el artículo 31.1 CE» ${ }^{72}$.

En función de lo anterior, el Tribunal Constitucional rechaza el primer motivo de inconstitucionalidad, ya que, se demuestra que el IDEC contiene una finalidad extrafiscal, como es la de armonizar la sujeción a gravamen de

${ }^{69}$ Vid., artículo 133.1 CE:» La potestad originaria para establecer los tributos corresponde exclusivamente al Estado, mediante ley».

${ }^{70} \mathrm{Vid}$., artículo 149.1.14. ${ }^{\mathrm{a}} \mathrm{CE}$ : «El Estado tiene competencia exclusiva sobre las siguientes materias: 14. ${ }^{\mathrm{a}}$ Hacienda general y Deuda del Estado».

71 Sentencia del Tribunal Constitucional 26/2015 de 19 de febrero, fundamento jurídico cuarto.

${ }^{72}$ Ibidem. 
la imposición sobre los depósitos en entidades de crédito, como anuncia el preámbulo de su norma reguladora, y además, cumple con lo expresado en el artículo 31.1 CE al gravar una capacidad económica, como es el mantenimiento de fondos de terceros, cualquiera sea su naturaleza jurídica, y que comporten la obligación de restitución, como establece el artículo 19.3 de la Ley 16/2012. Para el Alto Tribunal, el hecho de establecer un tipo de gravamen cero, no afecta a su posible declaración de legalidad, ya que, este tipo podrá ser modificado mediante Ley de presupuestos, según establece el artículo 19.11 de la Ley enjuiciada.

b) En segundo lugar, el Tribunal Constitucional analiza la posible vulneración de la reserva de ley orgánica contenida en el artículo 157.3 CE.

En relación a esta pretensión, el gobierno autonómico Catalán, esgrimía que solo modificando la LOFCA se podría conseguir crear un impuesto de semejantes características, pero esta cuestión es rechazada palmariamente por parte del tribunal, ya que «la creación del IDEC por el artículo 19 de la Ley 16/2012 no supone un desarrollo de la LOFCA, ya que su artículo 6.2, arbitra la posibilidad de que el Estado ejerza su potestad tributaria originaria estableciendo tributos sobre hechos imponibles gravado las comunidades autónomas ${ }^{73}$. En función de la anterior precisión, se rechaza el segundo motivo de inconstitucionalidad, ya que el Estado habría utilizado una posibilidad prevista en el ordenamiento.

c) El último motivo de inconstitucionalidad estudiado, se dirigía contra el apartado 13 del artículo 19 de la Ley 16/2012, que arbitra una medida de compensación aplicable a los tributos propios de las comunidades autónomas establecidos en una Ley aprobada con anterioridad al 1 de diciembre de 2012 .

Para poder resolver el mismo, el tribunal realiza una concreción del artículo 6.2 LOFCA, citado ya anteriormente en varias ocasiones en el presente trabajo. Este precepto obliga al Estado a establecer un sistema de compensación a las comunidades autónomas, cuando establezca un tributo que estuviera implantado anteriormente por ellas. Así, para el Tribunal Constituciconal «la exclusión de las medidas de compensación para aquellos tributos establecidos por las comunidades a partir del 1 de diciembre de 2012, obedece a una atención de aplicar el precepto en cuestión, lo que

${ }^{73}$ Sentencia del Tribunal Constitucional 26/2015 de 19 de febrero, fundamento jurídico quinto. 
obliga previamente al Estado a una previa labora de interpretación de su sentido y alcance» ${ }^{74}$.

En función de esta tarea de interpretación necesaria, considera el tribunal que el establecimiento de una fecha a partir de la cual no existe obligación de compensar a las comunidades autónomas que no hubieran aprobado su tributo con anterioridad, como ocurre en el caso presente, estableciendo la fecha de 1 de diciembre de 2012, es totalmente legal, «pues obedece a la finalidad, que no puede considerarse irrazonable, de evitar que durante el proceso de elaboración de la Ley 16/2012 pudieran algunas comunidades autónomas crear tributos equivalentes, en procedimientos legislativos más rápidos, con la finalidad de situarse acreedor de medidas de compensación ${ }^{75}$.

En vista de todos los argumentos anteriores el Tribunal Constitucional considera que el artículo 19 de la Ley 16/2012, de 27 de diciembre, es perfectamente legal y constitucional. Este fallo, afecta de manera significativa a la autonomía tributaria de las comunidades autónomas, así «a las comunidades autónomas, no solo les queda la búsqueda continua de objetos sobre los que eregir sus tributos propios, sino, a la vista de las recientes sentencias del TC, esperar que el Estado no imposibilite su exacción por medio de su plenipotenciaria potestad de coordinación o armonización» ${ }^{76}$.

\section{LA REGULACIÓN ACTUAL DEL IMPUESTO}

Actualmente, incluso con anterioridad al pronunciamiento del Tribunal Constitucional analizado en el apartado anterior, no se encuentra en vigor el artículo 19 de la Ley 16/2012, de 27 de Diciembre, por el que se crea el impuesto sobre depósitos de las entidades de crédito. En efecto, la compleja cronología de la vida del IDEC no se agota con lo analizado en el presente trabajo, sino que contiene más capítulos, y una larga vida futura.

En julio del 2014, el Gobierno Español crea el Real Decreto-ley 8/2014 de 4 de julio, de aprobación de medidas urgentes para el crecimiento, la competitividad y la eficiencia ${ }^{77}$, mediante el cual, modifica la normativa del impuesto sobre depósitos de entidades de créditos Estatal. En el preámbulo del citado texto legal, se encuentra la motivación de la reforma, que no es otra que buscar una verdadera armonización del tributo, al establecer que «la aprobación de impuestos autonómicos posteriores al inicio de la tramitación

${ }^{74}$ Ibidem., fundamento jurídico sexto.

75 Ibidem.

${ }^{76}$ García Moreno, Alberto, «El impuesto sobre depósitos: una materia imponible reservada al Estado», Carta Tributaria 4 (2015), 13.

77 Real Decreto-ley 8/2014 de 4 de julio, de aprobación de medidas urgentes para el crecimiento, la competitividad y la eficiencia, «BOE» núm. 163, de 5 de julio de 2014. 
legislativa del precepto por el que en dicha Ley se creó el Impuesto sobre los Depósitos en las Entidades de Crédito, hace necesaria esta modificación urgente con el objeto de garantizar una tributación armonizada de los depósitos constituidos en las entidades de crédito en todo el territorio español».

Este impuesto sigue conteniendo en esta regulación las mismas notas características que le define, es decir, se sigue configurando como un impuesto directo que grava la captación de fondos por partes de las entidades de crédito, siempre que de los mismos nazca la obligación de restituirlos. Los sujetos pasivos, o contribuyentes siguen siendo las entidades de crédito. Ahora bien, el artículo 124 del Real Decreto citado, introduce dos modificaciones sustanciales:

a) La primera modificación se introduce en la base imponible del tributo.

Como se recordará, este tributo estatal destacaba por una característica principal, como era el establecimiento de un tipo de gravamen cero, lo que conllevaba la ausencia de recaudación monetaria para la Hacienda Pública. Pues bien, ante las oleadas de críticas recibidas por esta actuación, aunque de carácter legal como estableció el Tribunal Constitucional, el Gobierno decide cambiar la base imponible del IDEC. Así, el tributo deja de ser un impuesto a tipo cero para tener un tipo de gravamen del $0,03 \%$ al aplicar sobre la base imponible. Con este nuevo tipo de gravamen, el Estado Español tiene previsto recaudar 375 millones de euros anuales. Esta modificación se encuentra reflejada en parte de los autores desde un punto de vista positivo, considerando entre otras cuestiones que «el tipo de gravamen reducido impide que puede considerarse que el mismo penalice el ahorro y se desincentive la financiación estable vía depósitos, al mismo tiempo que se garantiza la ansiada unidad de mercado al impedirse la diferente tributación por razón del territorio ${ }^{78}$.

b) La segunda gran modificación acaece en relación al tan discutido sistema de compensación previsto en el artículo 19 de la Ley 16/2012, a través, del cual solo se accede a compensar a las comunidades autónomas que tuvieran un impuesto sobre depósitos de créditos, en vigor, con anterioridad al 1 de diciembre de 2012.

A partir de la entrada en vigor de este Real Decreto-ley, se establece que «la recaudación obtenida se distribuirá a las Comunidades Autónomas en

78 García De Pablos, Jesús, «El impuesto sobre depósitos bancarios», Revista Quincena Fiscal 4, (2015), 10. 
función de donde radiquen la sede central o las sucursales de los contribuyentes en las que se mantengan los fondos de terceros gravados $\rangle^{79}$. De lo anterior se extrae, que ya no solo se compensarán a las comunidades de Extremadura, Andalucía y Canarias, sino que se compensará a todas las comunidades autónomas, siguiendo el criterio establecido anteriormente.

Ahora bien, el caos legislativo y judicial en relación a la regulación del tributo objeto de análisis, no se agota con la presente narración de acontecimientos, sino que continua. En efecto, la Generalitad Valenciana interpuso un recurso de inconstitucionalidad contra el artículo 124 del Real Decretoley $8 / 2014$, de 4 de julio de aprobación de medidas urgentes para el crecimiento, la competitividad y la eficiencia. El principal motivo de inconstitucionalidad aducido por el ejecutivo Valenciano, radicaba en una posible vulneración del artículo 86.1 de la Constitución Española ${ }^{80}$, artículo que establece que para crear un decreto-ley será necesario justificar una situación de extraordinaria y urgente necesidad.

El Gobierno Español, decide reaccionar a la interposición del recurso, y a un más que posible fallo en su contra del Tribunal Constitucional, ya que es difícil atisbar una situación de urgente necesidad para modificar el IDEC mediante la forma utilizada, y aprueba la Ley 18/2014, de 15 de octubre de aprobación de medidas urgentes para el crecimiento, la competitividad y la eficiencia ${ }^{81}$. Este ley recoge la misma modificación del artículo 19 de la Ley 16/2012, de 27 de diciembre, que la efectuada por el artículo 124 del Real Decreto-ley 8/2014, de 4 de julio.

Por tanto, la regulación actual del impuesto sobre depósitos de entidades de crédito, es la resultante de las modificaciones introducidas por la Ley 18/2014, de 15 de octubre de aprobación de medidas urgentes para el crecimiento, la competitividad y la eficiencia, sobre el artículo 19 de la Ley 16/2012, de 27 de diciembre. Pero, aquí no se acaba la problemática acerca de este impuesto, ya que anteriormente se anunciaba que la Generalitad Valenciana interpuso un recurso de inconstitucionalidad sobre el Real Decreto-ley 8/2014. En efecto, el Tribunal Constitucional se pronuncia acerca de la legalidad del citado Real Decreto-ley, en su sentencia número 211/2015 de 8 de octubre.

79 Artículo 124, apartado 14 del Real Decreto-ley 8/2014 de 4 de julio, de aprobación de medidas urgentes para el crecimiento, la competitividad y la eficiencia.

$80 \mathrm{Vid}$., artículo 86.1 CE: «En caso de extraordinaria y urgente necesidad, el Gobierno podrá dictar disposiciones legislativas provisionales que tomarán la forma de Decretosleyes y que no podrán afectar al ordenamiento de las instituciones básicas del Estado, a los derechos, deberes y libertades de los ciudadanos regulados en el Título I, al régimen de las Comunidades Autónomas ni al Derecho electoral general».

${ }^{81}$ Ley 18/2014, de 15 de octubre de aprobación de medidas urgentes para el crecimiento, la competitividad y la eficiencia, «BOE» núm. 252, de 17 de octubre de 2014. 
El tribunal tras dilucidar si existe una extraordinaria y urgente necesidad para modificar la regulación del IDEC mediante esta fórmula jurídica, llega a la conclusión de que «el Gobierno no ha aportado una justificación suficiente que permita apreciar la existencia del presupuesto habilitante de la extraordinaria y urgente necesidad requerido por el artículo 86.1 CE para el uso de la legislación de urgencia en relación con el artículo 124 del Real Decreto-ley 8/2014, lo que ha de determinar la declaración de inconstitucionalidad y nulidad de dicho artículo por vulneración del citado precepto constitucional». Por tanto, el Alto Tribunal declara el día 8 de octubre de 2015 inconstitucional este precepto, pero esta declaración, no afecta a la validez de la Ley 18/2014, de 15 de octubre de aprobación de medidas urgentes para el crecimiento, la competitividad y la eficiencia, que es donde se encuentra la última redacción del impuesto sobre depósitos de entidades de crédito Estatal, ya que además esta norma fue declarada constitucional por la sentencia número 102/2015 de 26 de mayo ${ }^{82}$ del Tribunal Constitucional.

Para concluir este apartado, y antes de expresar las conclusiones del autor respecto al presente trabajo, toca expresar que la actual regulación del tributo goza de mayor simpatía dentro de la doctrina, al considerar entre otras cuestiones que «podríamos decir que la nueva regulación establece, ahora sí, una tributación armonizada de los depósitos constituidos en las entidades de crédito, mediante el establecimiento de un tipo de gravamen del 0,03\%, al mismo tiempo que se establece un trato similar a todas las comunidades autónomas, mediante el nuevo sistema de compensación establecido» ${ }^{83}$.

\section{CONCLUSIONES}

El presente autor, tras analizar los acontecimientos que han narrado el surgimiento de la figura tributaria objeto de estudio, debe realizar una serie de conclusiones que pongan énfasis a las cuestiones más importantes, y expresen una opinión fundada acerca de las mismas.

PRIMERA.- El impuesto sobre depósitos de las entidades de crédito surge a través de una innovación tributaria autonómica. En este caso, es la Comunidad Autónoma de Extremadura su creadora. Dicha Comunidad, es un ejemplo, de una situación preocupante y palmaria, como es la falta de ingresos de las mismas, y ante ésta situación, las autonomías reaccionan

${ }^{82}$ Sentencia número 102/2015 de 26 de mayo del Tribunal Constitucional, fundamento jurídico sexto: «no es tarea del Tribunal determinar cuál habría sido la forma más adecuada de coordinar los hechos imponibles gravados por el impuesto sobre depósitos, ni muchos menos cual debería haber sido el método más idóneo para compensar las eventuales perdidas de recaudación».

${ }^{83}$ García De Pablos, Jesús, op.cit., 15. 
creando nuevas figuras tributarias. La regulación de la autonomía financiera de las Comunidades Autónomas se encuentra establecida en la Ley Orgánica 8/1989, de 22 de Septiembre, de Financiación de las Comunidades Autónomas. Esta Ley Orgánica ha sufrido varias reformas, la última en el año 2009, pero todavía sigue sin ser capaz de dar una respuesta válida a los problemas competenciales surgidos entre el Estado y las Comunidades Autónomas, situación que puede observarse perfectamente, en las sucesivas leyes Autonómicas y Estatales sobre el impuesto objeto de debate, y los necesarios pronunciamientos del Tribunal Constitucional acerca de las mismas.

SEGUNDA.- El impuesto sobre depósitos de las entidades de crédito, en todas las regulaciones existentes, se contempla como un impuesto directo, que grava los fondos de las entidades de crédito, de los que surja obligación de restitución, situadas en el territorio estatal o autonómico. Este tributo, permite a las entidades de crédito contribuir con el sostenimiento de los gastos públicos, y además en todas las regulaciones autonómica, venía acompañado de un sistema de deducciones, motivadas en incentivar las inversiones en los territorios autonómicos, hasta el punto, como ocurría en la regulación Extremeña objeto de análisis, de conseguir deducir el impuesto hasta una tasa cero. Este sistema de deducciones, como se ha expuesto anteriormente ha sufrido una importante critica desde numerosos sectores, ya que esta medida podría afectar a la libre circulación de capitales reconocida por el Tribunal de Justicia de la Unión Europea, pero el presente autor, debe compartir el criterio establecido en la sentencia del Tribunal Constitucional número 210/2012 de 14 de noviembre, donde se declara que este sistema de deducciones es perfectamente licito, y obedece a un fin extrafiscal de la figura tributaria.

TERCERA.- Como se ha analizado con detalle en el presente trabajo, la sentencia citada anteriormente, declara legal el impuesto Extremeño. Ante esta declaración, la reacción del Estado no se hace esperar, y crea a través del artículo 19 de la Ley 16/2012, de 27 de diciembre, un impuesto Estatal. La única finalidad por la que se crea este tributo, teniendo que estar en este punto el presente autor de acuerdo con la doctrina mayoritaria expuesta, es la de limitar la autonomía financiera de las comunidades autónomas. Esta limitación es clara y palmaria desde el momento inicial que el Estado decide crear este tributo a tipo cero, lo que suponía la ausencia de recaudación de cantidad monetaria por el mismo, actuando de esta manera, representando posiciones más propias de un abogado defensor de las entidades de crédito, que de un legislador que quiere armonizar el sistema tributaria en relación con el impuesto en cuestión.

CUARTA.- Ahora bien, la polémica acerca de la regulación Estatal del impuesto sobre depósitos de las entidades de crédito, no se agota en la inclusión de un tipo de gravamen cero, sino que contiene dos puntales necesarios de matizar. En efecto, tanto el método de aprobación del tributo, como el 
sistema de compensación establecido en el mismo, son muy controvertidos. En relación al método de aprobación, el legislador utilizó una Ley orgánica, cuestión muy debatida por la doctrina, ya que si la intención del Estado era la verdaderamente expresada en su preámbulo, es decir, la armonización del sistema tributario, ésta función debe realizarse a través de una Ley orgánica como establece la Constitución Española. Respecto a la segunda cuestión, el sistema de compensación introducido por la norma, ya explicado anteriormente, solo permitía la compensación a 3 Comunidades Autónomas: Extremadura, Andalucía y Canarias. De todo lo anterior, se puede deducir, que la primera regulación estatal acerca de este tributo era muy deficiente, fruto de una redacción acelerada, para anticiparse a los posibles tributos autonómicos, y llena de incorreciones que demuestran que su único fin era perjudicar a las Comunidades Autónomas, protegiendo los intereses de las entidades de crédito.

QUINTA.- El Tribunal Constitucional resuelve las dudas acerca de la legalidad de la Ley Estatal, en su sentencia número 26/2015 de 19 de febrero. Ahora bien, el presente autor no puede compartir algunos de los argumentos expresados por el Tribunal y plasmados en el apartado cuarto del presente trabajo. Fundamentalmente, el aspecto relacionado a la finalidad recaudatoria que debe tener todo impuesto, proporcionando ingresos a la Hacienda Pública, nota característica que establece el artículo 31 de la Constitución Española. El Tribunal considera que se cumple este requisito, debido a que en el tributo se aprecian dos cuestiones, la existencia de un fin extrafiscal de la normativa, cuestión más que dudosa, ya que de su regulación con un tipo cero se puede desprender que si tuviera un fin extrafiscal la misma, sería la protección de los intereses de las entidades de crédito, y no por supuesto la armonización del sistema tributario, y en segundo lugar, la existencia de un fin recaudatorio por el hecho de que la propia Ley contempla que dichos tipos pueden ser modificados. No puede compartir el presente autor lo anterior, ya que el hecho de que la propia Ley incluya esa previsión de modificación, no la convierte en una norma con fin recaudatorio, debido a que cualquier norma puede ser modifica en cualquier momento.

SEXTA.- Sin incidir especialmente en las normativas autonómicas surgidas tras el pronunciamiento del Alto Tribunal en el año 2012, todas declaradas inconstitucionales por infringir el artículo 6.2 LOFCA, se debe precisar en último lugar, la redacción actual del impuesto Estatal. Actualmente, la última redacción vigente es la otorgada por la Ley 18/2014, de 15 de Octubre, declarada constitucional por el Tribunal Constitucional, mediante la sentencia número 102 de 26 de mayo. Esta regulación, ya si establece un tipo de gravamen, concretamente del $0,03 \%$, y establece un nuevo sistema de compensación, que permite distribuir los ingresos obtenidos por el Estado entre todas las Comunidades Autónomas. El sistema de reparto es el 
siguiente: Extremadura, Andalucía y Canarias, recaudan directamente este impuesto debido a que todavía no se ha introducido la modificación que configure el tributo como cedido, mientras que el resto de Comunidades Autónomas reciben una cantidad por parte del Estado, en función, de las entidades de crédito que se encuentren sitas en las mismas. La actual regulación, estableciendo un tipo de gravamen, ya si puede considerarse que contenga un verdadero fin armonizador, resolviendo la principal controversia acaecida con la regulación primaria del tributo estatal.

\section{BIBLIOGRAFÍA}

Álvarez Arroyo, Francisco, «Incidencia de las Comunidades Autónomas en el sistema financiero y tributario local: Análisis jurídico del artículo 6.3 LOFCA y sus posibilidades de aplicación», Revista Quincena Fiscal 14 (1994).

Calvo Ortega, Rafael, Curso de Derecho Financiero. Tomo I. Derecho Tributario (Madrid: Thomson Civitas, 2009).

CheCA GonzÁlez, Clemente, «El impuesto sobre tierras infrautilizadas de la Comunidad Autónoma Andaluza. Comentario a la Sentencia TC 37/1987 de 26 de Marzo», en Impuestos. Revista de Doctrina, Legislación y Jurisprudencia, tomo I (1987)

- Los impuestos de las Comunidades Autónomas (Madrid: editorial Aranzadi, 2002).

CruZ Amorós, Miguel, Esquivel FernÁNDEZ, Ariane, «El impuesto extremeño sobre depósitos de las entidades de crédito», Diario La Ley 3159 (2013).

FALCÓN Y TELLA, Ramón, «El impuesto sobre los depósitos de las entidades de crédito: sobre la necesidad de un nuevo modelo para articular la potestad tributaria estatal y autonómica», Revista Quincena Fiscal 20 (2013).

GALAPERo Flores, Rosa, «El carácter constitucional del impuesto sobre los depósitos de las entidades de crédito de la comunidad autónoma de Extremadura», Anuario de la Facultad de Derecho vol. XXI (2003).

—_ «El impuesto sobre los depósitos de las entidades de crédito de la comunidad autónoma de Extremadura. La declaración de su constitucionalidad por el Tribunal Constitucional», Impuestos. Revista de Doctrina, Legislación y Jurisprudencia 6, Sección Divulgación, Junio (2013).

García De Pablos, Jesús, «El impuesto sobre depósitos bancarios», Revista Quincena Fiscal 4 (2015).

García Moreno, Alberto, «El impuesto sobre depósitos: una materia imponible reservada al Estado», Carta Tributaria 4 (2015).

GARCÍA NovoA, César, «El futuro de la fiscalidad autonómica sobre los depósitos bancarios», Revista catalana de dret púbic 46 (2013).

JOVER LORENTE, José Manuel, «La responsabilidad social corporativa como fin ultrafiscal subyacente del impuesto extremeño sobre los depósitos de las entidades de crédito», Impuestos. Revista de Doctrina, Legislación y Jurisprudencia 19, Octubre (2012). 
Mata Sierra, María, Carbajo Nogal, Carlos, «Conflictos entre la Hacienda estatal y las autonómicas en el Impuesto sobre los depósitos de las entidades de crédito», Revista Quincena Fiscal 18 (2013).

Merino Jara, Isaac, LuCAs Durán, Manuel, Fernández Amor, José Antonio, García Calvente, Yolanda, García Luis, Tomás, Manzano Silva, Elena, Ruiz GariJo, Mercedes, Vaquera García, Antonio, Derecho Financiero y Tributario: Parte General (Madrid: editorial Tecnos, 2011).

PÉrez ZúÑIGA, José María, «El impuesto estatal sobre depósitos en entidades de crédito», Actualidad Administrativa 6 (2013).

\section{FUENTES LEGISLATIVAS}

Constitución Española, «BOE» núm. 311, de 29 de diciembre de 1978.

Ley Orgánica 8/1980, de 22 de septiembre, de Financiación de las Comunidades Autónomas, «BOE» núm. 236, de 01/10/1980.

Ley 39/1988, de 28 de diciembre, reguladora de las Haciendas Locales, «BOE» núm. 313, de 30 de diciembre de 1988.

Real Decreto Legislativo 1175/1990, de 28 de septiembre, por el que se aprueban las tarifas y la instrucción del Impuesto sobre Actividades Económicas, «BOE» núm. 234, de 29 de septiembre de 1990.

Ley $37 / 1992$, de 28 de diciembre, del Impuesto sobre el Valor Añadido, «BOE» núm. 312, de 29 de diciembre de 1992.

Ley de la Asamblea de Extremadura 14/2001 de 29 de noviembre, reguladora del impuesto sobre depósitos de las entidades de crédito, «BOE» núm. 31, de 5 de febrero de 2002.

Ley 58/2003, de 17 de diciembre, General Tributaria, «BOE» núm. 302, de 18 de diciembre de 2003.

Ley Orgánica 3/2009, de 18 de Diciembre, de modificación de la Ley Orgánica de financiación de las comunidades autónomas, «BOE» núm. 305, de 19 de diciembre de 2009.

Ley de presupuestos generales para Asturias de 2013, «BOPA», núm. 300, de 29 de diciembre de 2012.

Decreto Ley 5/2012 de 18 de diciembre de 2012, «DOGC» núm. 6277, de 19 de diciembre de 2012.

Ley 5/2013, de 23 de diciembre, de medidas fiscales, de gestión administrativa y financiera y de organización de la Generalitat, «DOCV» núm. 7181 de 27 de Diciembre de 2013.

Ley 18/2014, de 15 de octubre de aprobación de medidas urgentes para el crecimiento, la competitividad y la eficiencia, «BOE» núm. 252, de 17 de octubre de 2014.

Real Decreto-ley 8/2014 de 4 de julio, de aprobación de medidas urgentes para el crecimiento, la competitividad y la eficiencia, «BOE» núm. 163, de 5 de julio de 2014.

Decreto Legislativo 1/2014, de 23 de Julio por el que aprueba el texto refundido de las disposiciones leales del Principado de Asturias en materia de tributos propios, «BOPA» núm. 175, de 29 de julio de 2014. 


\section{JURISPRUDENCIA}

Sentencia del Tribunal Constitucional número 210/2012 de 14 de noviembre. El Tribunal Constitucional desestima el recurso de inconstitucionalidad interpuesto por el Presidente del Gobierno contra la Ley de la Asamblea de Extremadura 14/2001 de 29 de noviembre, reguladora del impuesto sobre depósitos de las entidades de crédito.

Sentencia del Tribunal Constitucional 53/2014, de 10 de abril. Esta sentencia establece que dentro de un tributo, pueden coexistir tanto el fin fiscal como el fin extrafiscal.

Sentencia del Tribunal Constitucional número 26/2015 de 19 de febrero. El Tribunal Constitucional desestima el recurso de inconstitucionalidad interpuesto por el Parlamento de Cataluña contra el artículo 19 de la Ley 16/2012, de 27 de diciembre, por la que se crea el impuesto sobre depósitos en las entidades de crédito.

Sentencia del Tribunal Constitucional número 30/2015 de 19 de febrero. El Tribunal Constitucional estima el recurso de inconstitucionalidad contra el artículo 161 de la Ley de las Cortes Valencianas 5/2013, de 23 de diciembre, por la que se crea el impuesto sobre depósitos de créditos.

Sentencia del Tribunal Constitucional número 102/2015 de 26 de mayo. El Tribunal Constitucional desestima el recurso de inconstitucionalidad interpuesto por el Consejo de Gobierno del Principado de Asturias contra el artículo 124 de la Ley 18/2014, de 15 de octubre, mediante el que se crea el impuesto sobre depósitos de entidades de crédito.

Sentencia del Tribunal Constitucional número 107/2015 de 28 mayo. El Tribunal Constitucional estima el recurso de inconstitucionalidad interpuesto por el Presidente del Gobierno contra el Decreto Ley 5/2012 de 18 de diciembre de 2012 por el que se aprueba el impuesto sobre depósitos de entidades de crédito.

Sentencia del Tribunal Constitucional número 202/2015 de 24 de Septiembre. El Tribunal Constitucional estima el recurso de inconstitucionalidad interpuesto por el Presidente del Gobierno contra los artículos 52 a 64 del Decreto legislativo 1/2014, de 23 de julio del Principado de Asturias, donde se encuentra regulado el impuesto sobre depósitos de entidades de créditos.

Sentencia del Tribunal Constitucional número 211/2015 de 8 de octubre. El Tribunal Constitucional estima el recurso de inconstitucionalidad interpuesto por la Generalitat Valenciana contra el artículo 124 del Real Decreto-ley 8/2014, de 4 de julio, de aprobación de medidas urgentes para el crecimiento, la competitividad y la eficiencia por posible vulneración del artículo $86.1 \mathrm{CE}$ y declara su inconstitucionalidad.

TITLE: The tax on deposits of credit institutions: paradigmatic example of limited financial autonomy of the regions

RESUMEN: El presente trabajo tiene como objeto analizar la figura del impuesto sobre depósitos de las entidades de crédito. Esta figura tiene su origen en la comunidad autónoma de Extremadura, que haciendo uso de su potestad tributaria, decide en el año 2001 gravar los depósitos de las entidades de crédito. La autonomía financiera de las comunidades 
autónomas, es una cuestión compleja, siendo el principal fondo del asunto que reside en la regulación del impuesto sobre depósitos de las entidades de crédito. Esta decisión por parte de Extremadura generó una enorme polémica, que ha provocado una sucesión de normas autonómicas y estatales sobre este impuesto, y como no, varios pronunciamiento del Tribunal Constitucional que serán objeto de estudio en el presente trabajo.

PALABRAS CLAVE: Depósitos, créditos, tributo, hecho imponible, inconstitucional.

ABSTRACT: This paper aims to analyze the figure of tax deposits of credit institutions. This figure stems from the autonomous community of Extremadura, making use of their fiscal sovereignty, he decided in 2001 to tax deposits of credit institutions. The financial autonomy of the regions is a complex issue, with the main substance of the matter lies in the regulation of tax deposits from credit institutions. This decision by Extremadura generated a huge controversy, which has caused a series of regional and state rules on this tax, and of course, several ruling of the Constitutional Court that will be studied in this paper.

KEYWORDS: Deposit, credit, tax, taxable event, unconstitutional

RECIBIDO: 26.01 .2016

ACEPTADO: 19.12 .2016 